Cahiers $d u$ MONDE RUSSE

\section{Cahiers du monde russe}

Russie - Empire russe - Union soviétique et États indépendants

45/3-4 | 2004

Varia

\title{
Simon Franklin, Emma Widdis, eds., National identity in Russian culture
}

Marlène Laruelle

\section{OpenEdition}

\section{Journals}

Édition électronique

URL : https://journals.openedition.org/monderusse/4216

DOI : 10.4000/monderusse.4216

ISSN : $1777-5388$

Éditeur

Éditions de l'EHESS

\section{Édition imprimée}

Date de publication : 1 juillet 2004

Pagination : 734-736

ISBN : 2-7132-2009-2

ISSN : $1252-6576$

Référence électronique

Marlène Laruelle, "Simon Franklin, Emma Widdis, eds., National identity in Russian culture », Cahiers du monde russe [En ligne], 45/3-4 | 2004, mis en ligne le 03 juin 2009, consulté le 03 septembre 2022 URL : http://journals.openedition.org/monderusse/4216; DOI : https://doi.org/10.4000/monderusse. 4216

Ce document a été généré automatiquement le 3 septembre 2022.

Tous droits réservés 


\title{
Simon Franklin, Emma Widdis, eds., National identity in Russian culture
}

\author{
Marlène Laruelle
}

\section{RÉFÉRENCE}

Simon FRANKLIN, Emma WIDDIS, eds., National identity in Russian culture.

Cambridge-New York, Cambridge University Press, 2004, 240 p.

1 L'objectif de ce recueil d'articles est d'introduire la thématique identitaire dans l'histoire de la culture ou, tout aussi bien, d'ancrer les recherches menées en histoire de la culture dans les réflexions sur l'identité russe. Cette approche postule que les identités nationales relèvent de constructions politiques et sociales, de processus et non de résultats qu'il faut étudier en tant que tels. L'ouvrage n'a donc pas pour but de présenter au lecteur une vision cohérente de ce que serait la "russité», telle qu'elle a pu être pensée par les Russes tout comme par les Occidentaux. Il cherche plutôt à montrer que, malgré cette question posée sur un mode essentialiste, les réponses méritent d'être analysées pour ce qu'elle sont, c'est-à-dire des produits culturels. Il se propose alors de suivre divers modes d'invention, dans le domaine culturel, du thème de l'identité collective et l'ancrage social dont il bénéficie en étant considéré comme « naturel ». Le plan de l'ouvrage, divisé en quatre parties, reflète cet objectif ambitieux de mener en parallèle une réflexion généraliste et de l'illustrer par un exemple précis.

2 Il est tout d'abord question de l'identité russe dans le temps et dans l'espace, afin de mieux saisir comment le pays fut appréhendé en tant qu'entité temporelle ou physique. Simon Franklin et Emma Widdis analysent à ce titre la construction contemporaine d'une continuité temporelle de l'État au travers de séries de timbres et de billets de banque, puis s'interrogent sur la thématique - classique depuis le XVIII siècle, mais étudiée dans le cas présent par le biais du film de Ivan Pyr'ev Le Dit de la terre sibérienne (1947) et de cartes datant de la période stalinienne - de l'espace (prostor) russe, systématiquement défini comme « immense », « infini », « sans frontières », etc. 
La deuxième partie est consacrée aux identités dites "contrastives ", c'est-à-dire à l'opposition entre «nous » et " eux » : comment les Russes se sont-ils définis, quels ont été les critères permettant de dépasser les clivages sociaux et de créer une " communauté imaginée » se reconnaissant dans de mêmes clichés? Au premier terme, "nous", est consacré un article de Hubertus F.Jahn sur la définition de l'identité nationale dans les grandes œuvres de la littérature classique, mais également, de manière plus originale, sur la représentation de la « russité » dans les chansons et le théâtre de rue au XIX ${ }^{e}$ siècle. Au second terme, " eux ", s'attèle un article de Anthony Cross qui retrace le rapport aux étrangers, principalement aux Occidentaux, dans l'histoire russe, depuis l'usage englobant du terme de Nemcy, au Moyen Âge, pour tous ceux qui étaient venus de l'Ouest, jusqu'à la francophilie et l'anglophilie des classes dirigeantes tsaristes.

La troisième section est centrée sur les «identités essentielles» et analyse la construction d'argumentations primordialistes qui se présentent comme des explications totalisantes et définitives. Ainsi, tant l'orthodoxie (Simon Franklin) que l'art (Marina Frolova-Walker étudie le cas de la musique), la langue (Boris Gasparov), ou bien encore le terme de byt (la vie quotidienne, mot très marqué par un usage folklorisant à l'époque soviétique, comme l'explique dans son article Catriona Kelly) constituent pour certains penseurs russes des éléments matriciels permettant de donner un contenu « objectif » à l'identité nationale.

5 Enfin la dernière partie, qui regroupe des articles de Lindsey Hughes et de Stephanie Sandler, est consacrée aux symboles publics et institutionnalisés de l'identité que sont les monuments publics, appréhendés comme des "lieux de mémoire " (l'église SaintBasile sur la place Rouge et la cathédrale du Christ-Sauveur tout juste reconstruite, ainsi que les statues de Puškin qui dominent l'espace urbain), et s'interroge sur la politique de " patrimonialisation » en vigueur actuellement en Russie.

6 La singularité de l'ouvrage réside donc précisément dans ce patchwork de thématiques, traitées sur le long terme historique souvent depuis leurs « origines », ou tout au moins depuis le XVIII siècle, et s'appuyant tant sur les clichés les plus banals (pays du froid, etc.) utilisés pour définir la Russie que sur des œuvres célèbres. En prenant le parti d'assumer ce caractère multiforme et la diversité des approches de chaque auteur, le livre invite à repenser des arguments qui semblent souvent trop connus (le rapport à l'espace, à l'Occident, à l'orthodoxie) sous des angles d'approche novateurs, renouvelés au travers d'un exemple précis, film, livre, carte, monument... Il présente une vue d'ensemble des thématiques identitaires russes, souvent bien connues des spécialistes, mais qui restent difficiles d'accès pour un public plus large. Il offre également de multiples pistes de recherche en histoire de la culture et démontre la richesse d'une approche à la fois historique et anthropologique de la culture, qui permet de contourner les écueils essentialistes d'une réflexion sur l'identité nationale et d'en faire au contraire un mode d'accès à la société russe. 